\title{
A Taxonomy of Suburban Office Clusters: The Case of Toronto
}

\author{
Gary Pivo \\ Paper first submitted, May 1991; \\ in final form, January 1992
}

\begin{abstract}
Summary. Metropolitan plans are commonly based on a system of suburban office clusters. The large variation among recent plans suggests a poor understanding of their nature and impacts. A taxonomy of office clusters could provide a necessary framework. Six hypotheses on the type, frequency, location, employment base and travel characteristics of suburban clusters were tested in a case-study of the Toronto region. Six physical types were identified and found to be associated with certain locations, employment activities and travel mode characteristics. The Toronto metropolitan plan was found to be successful when it conformed with these findings and unsuccessful when it did not. The results lead to provisional guidelines for future metropolitan plans.
\end{abstract}

\section{Introduction}

As a result of office suburbanisation, urban planners have become increasingly concerned with suburban office clusters (Pivo, 1990). ${ }^{\text {T }}$ They are particularly interested in the various types that will develop, where they will locate, their physical and economic characteristics and the impacts they will have on infrastructure and the urban environment.

A categorical system or taxonomy of office clusters (Nachmias and Nachmias, 1987) could help planners with their concerns. It could use certain office cluster characteristics, such as size, density and location, which are useful for predicting other characteristics of concern to urban planners, such as frequency of occurrence or impact on traffic, to determine the different types of office clusters that are known to exist (Hempel, 1965).

Such a system could go on to identify other factors apart from cluster characteristics, such as regional population, the degree of highway investment, or land use policies, that might alter the characteristics of the various types of clusters. For example, large and dense types of suburban office clusters, sometimes called secondary downtowns, may compose a larger proportion of all suburban office clusters and generate a larger percentage of transit trips in regions with a less developed freeway system. If such a theory could be developed, planners may be able to use it to predict or alter the type of clusters that would occur in a given region as well as their frequency, location and impacts.

It would seem there are at least four prerequisites to being able to develop a useful taxonomy of office clusters. First, different types of clusters, based on one or more characteristics, must exist and be 
different enough from one another to justify the creation of distinct types. Otherwise it would be more accurate to describe a continuum of clusters rather than separate types. Secondly, the types of clusters that are defined must be associated with other characteristics of interest to urban planners-otherwise the clusters would serve no useful purpose. Thirdly, the types must normally occur when certain conditions are present within a single region and across regions-otherwise it would be impossible to predict the appearance of a given type of cluster. Finally, the effects each type of cluster has on its environment must be similar under similar conditions -otherwise it would be impossible to predict the impacts of a given type of cluster.

These prerequisites do not require all regions to have the same mix of cluster types, nor do they require a given type of cluster to have the same effects under all circumstances. What is required, however, is that certain types be found under certain conditions and that they have similar effects under similar circumstances. These conditions and circumstances may be economic, physical, political or otherwise, as long as they lead to predictable outcomes.

The occurrence or effect of the various types of clusters may result as much or more from land use politics and developer speculation as from rational decisions taken by office tenants. This will not render a taxonomy infeasible as long as the particular conditions of these factors result in similar outcomes whenever they occur within and across regions.

There are reasons to believe that it may be feasible to create a taxonomy of office clusters. First, the author's previous empirical research found several similarities in suburban office development patterns across different regions (Pivo, 1990). This suggests that similar forces may be at work to shape office development in different regions. Secondly, a large body of research on intra-urban spatial structure (Goodall, 1972; Clark, 1982) suggests that urban development does follow certain similar patterns from region to region. Even though the pattern of office development, like that of residential development, may result at least as much from speculative developers interacting with public land use policy-makers as from rational economic location decisions of office tenants, patterns in the forces that shape office development may result in patterns in the form of office development.

This paper gives the results of the author's initial work on this problem in which a typology of office clusters was developed for the Toronto region. Empirical data were used to test a variety of hypotheses about the presence of different cluster types and their characteristics. While a taxonomy could be based upon a number of different variables-such as physical factors, environmental impact or economic function-physical factors, in particular size, density and accessibility, were used for reasons which will be discussed later.

This paper is intended to demonstrate the feasibility of further work in this direction. Comparable studies of other regions will be necessary in order to establish a general theory that would be transferable across regions. The study of a single region can tell us whether different types of clusters exist, how different the types are from one another and how strongly the types are associated with characteristics of interest to urban planners. However, it cannot tell us whether similar types exist in other regions and the degree to which regional conditions affect their frequency or impact on the urban environment.

Research that helps to improve the consistency between plans and actual development would be of significant value. This can be illustrated by the high-capacity transit planning currently underway in the Seattle region of Washington State. The success of the effort will partly depend upon the ability of planners to predict or shape the future pattern of office clusters and their transport requirements so that 
Table 1. Suburban office clusters in recent regional plans

\begin{tabular}{lll}
\hline Place & Plan & Concept \\
\hline Seattle & $\begin{array}{l}\text { Puget Sound Council of Govts, } \\
\text { Vision 2020 Plan, 1990. }\end{array}$ & $\begin{array}{l}\text { Hierarchy of about 15 'central places' that } \\
\text { focus new employment in mixed-use, } \\
\text { higher density, transit-oriented clusters. }\end{array}$ \\
& $\begin{array}{l}\text { Southern California Association } \\
\text { of Governments, Regional } \\
\text { Transportation Plan, 1984 }\end{array}$ & $\begin{array}{l}\text { Four 'levels' of clusters, varying in size, } \\
\text { density and importance. Approximately } \\
69 \text { clusters throughout the region. } \\
\text { Characterised by size with one Level One, } \\
18 \text { Level Two, 50 Level Three and an } \\
\text { unidentified number of Level Four } \\
\text { clusters. }\end{array}$ \\
Phoenix & $\begin{array}{l}\text { City of Phoenix, Urban Villages } \\
\text { Plan, 1985. }\end{array}$ & $\begin{array}{l}\text { Nine Urban Village Cores that contain } \\
\text { the greatest intensity office, retail, } \\
\text { entertainment, cultural, residential, hotel } \\
\text { and some industrial uses in a pedestrian- } \\
\text { oriented environment. } \\
\text { Six Regional Town Centres with higher } \\
\text { density residential and office development } \\
\text { which focus retail, educational, cultural } \\
\text { and community facilities. }\end{array}$ \\
& $\begin{array}{l}\text { Greater Vancouver Regional } \\
\text { District, The Livable Region }\end{array}$ & $\begin{array}{l}\text { Mixed-use suburban centres on a rapid } \\
\text { transit network in a hierarchy including } \\
\text { one Central Area, two Major Clusters and } \\
\text { four Intermediate Clusters. }\end{array}$ \\
\hline Toronto & Municipality of Metropolitan \\
& $\begin{array}{l}\text { Toronto, Official Plan for the } \\
\text { Urban Structure, 1980. }\end{array}$ &
\end{tabular}

investments in transport facilities and programmes can be co-ordinated with future patterns of office development. If the planners make inaccurate projections or cannot shape office development to conform with their plans, then transit ridership may be lower than predicted, requiring higher transit subsidies. A theory of office clusters, that tells the planners the number, location and transport impacts of the various types of office clusters that are likely to occur, could help them avoid costly planning errors.

The author's review of recently adopted regional plans indicates that planners are not being guided by a common theory of office clusters. Table 1 shows that plans for Seattle, Los Angeles and Toronto are built on a size-based hierarchy of clusters while plans for Phoenix and Vancouver are built on clusters that would be roughly equal in size. The Seattle and Los Angeles plans include large and small clusters while other plans include only large clusters. The num- ber of planned clusters per capita ranges from 1 per 160000 persons in the Seattle region to 1 per 500000 in the Toronto region. The only similarity among the plans is their tendency to conceive of clusters in physical terms and, particularly for larger clusters, to see them as higher intensity, mixed-use, pedestrian and transit-oriented places.

\section{Previous Work}

Several previous authors have mentioned different types of suburban office clusters. One of the first classification systems was offered by Daniels (1974). He described four types which he called large clusters, small clusters, isolated office blocks, and office parks. He used size, density and location to build the classification scheme and associated each physical type with certain land use, economic or transport characteristics. The Daniels method was to use physical factors as criteria for member- 
ship in a given type of office cluster and to use the physical types to predict other characteristics.

Baerwald (1982) repeated this method when he used the physical concepts of areal form, location and nucleus to describe two types of land use concentrations which he called clusters and corridors. Like Daniels, he explored the types of land use activities and traffic conditions associated with each type. However, his work presents evidence on only one example of each type leaving some doubts about its external validity.

A more extensive study by Hartshorn and Muller (1986) combined physical and employment traits to develop various sub-types of Baerwald's clusters and corridors, such as the high-tech corridor and the regional mall cluster. The study presented a good deal of information on the transport, land use and economic characteristics of each type. However, like the other studies, it did not systematically and quantitatively relate the types to their characteristics. Consequently, it is more theoretical and less useful for planning applications.

The most rigorous analysis to date, also in the tradition of Daniels, was done by Cervero (1989). Like his predecessors, he used physical factors to identify various types of suburban office clusters. He also quantified their traffic, land use and employment characteristics. The major limitation of his work was its focus on large and prominent clusters, leaving out the more common, smaller varieties, thereby providing only a partial view of office development in any single region.

In contrast to these previous efforts, this study was designed to be a more systematic and comprehensive assessment of office clusters. An attempt was made to be systematic by quantitatively relating characteristics of clusters to issues of importance to planners. Comprehensiveness was sought by examining the full range of clusters that exist in the study region.

\section{Hypotheses}

Six hypotheses were tested in the study. They are presented below with their theoretical basis. Most of them are derived from theories that deal with location decisions of office firms, uses that are attracted to types of development sites or commuting behaviour of office workers.

Hypothesis 1: Each office cluster is not unique. There are discrete types with distinctive characteristics.

A number of different office cluster characteristics could be used to group clusters into types. For example, clusters could be grouped physically, economically, demographically or using some combination of the three. Finding the characteristics that are most useful for a theory of office clusters is a basic problem for this area of research. A variety of criteria could be used to determine the best discriminating characteristics including the ability to differentiate among clusters, the ability to create discrete groups, the ability to generate types that are highly correlated with other characteristics of interest to urban planners and the practicality of using them to distinguish different types of clusters.

The present study used physical characteristics, in particular cluster size, density and accessibility, to distinguish between different types of clusters. These were selected because they are basic building blocks for land use planning and are known to be related to various issues associated with office development, such as traffic and the journey-to-work.

It goes beyond the scope of this study to explore the usefulness of other discriminating factors, but this should be done in future studies. It may be the case, for example, that economic or demographic factors are very useful in predicting the level of traffic generated by office clusters and should be combined with or used instead of physical factors to distinguish types of clusters. It may also be the case 
that there is a strong enough correlation between the physical, economic and social characteristics of clusters to use physical factors as a proxy for the others. For example, the level of income among the workforce of a cluster may be positively correlated with the density of development.

Various theoretical perspectives suggest that it should be possible to observe physical types of clusters with distinctive characteristics. For example, industrial location theory suggests that similar office activities will seek locations that suit their production requirements for space, information, labour and other factors of production. There is evidence to suggest that certain types of office activities are better suited to certain types of physical development (Dowall, 1988; Whyte, 1990). If the satisfaction of production requirements is related to the physical type of cluster in which an office activity occurs then office activities will be attracted to clusters with locational or physical properties that are most suited to their requirements. The result will be that different physical types of office clusters will emerge in relation to the different types of office activities and their production requirements (Clark, 1982).

Another perspective holds that most office tenants are recruited after development occurs and therefore it is more useful to focus on the supply side of the development process. Urban land use theory, for example, focuses on the characteristics of development sites and predicts the type of development, including office clusters, that will be associated with various development sites as a result of their attributes, particularly their accessibility. According to this view, the attributes of different sites vary, causing the character of development to vary from site to site. Different physical types of office clusters should therefore be expected to arise from the varying attributes of sites where office development occurs.

Other theoretical perspectives which focus on the supply side of development focus on behavioural or politicaleconomic forces that shape development. According to these views, the types of clusters that emerge would depend on the behaviour of political interaction of office developers and other actors in the planning process. The types of clusters that are observed would be explained by the interests that predominate in the land use planning process. Different physical types of clusters would emerge that match the preference and strength of different interest groups. Where growth-control interests prevail, lower density clusters would be found. Where growth boosters prevail, more high-rise development would occur. Variations in the political landscape would generate the various types of office clusters.

Ultimately, one of these theories may be better able to explain the distribution of physical types of office clusters that are observed in the urban landscape. However for the purposes of this paper, it is enough that they all suggest that certain discrete physical types of office clusters can be found.

Hypothesis 2: The frequency with which each type of cluster occurs is inversely related to its size and density. As a result, cluster types fall into size- and intensitybased hierarchies.

Size- and intensity-based hierarchies probably result from competition for the most accessible locations. This raises the land rents of certain locations which stimulates higher intensity development by encouraging the substitution of capital for land. This process of competition for a limited number of attractive locations results in a small number of large and dense clusters. Offices and other uses with requirements that can be satisfied in less accessible locations can choose from a larger number of optional locations. This larger supply of possible locations, together 
with less competition for them, is likely to generate a larger number of smaller, lower density types of office clusters.

Hypothesis 3: Larger and denser types of clusters will be found at more accessible locations.

The largest and most intense office clusters should be found at the most accessible locations because of the economic advantages of accessibility (Sullivan, 1990). The advantages include greater access to labour, informal information networks, faceto-face contacts, business services and visibility (Whyte, 1990). Because of their economic superiority, these locations should attract a larger number of firms which should generate greater competition for the available space. This would drive up land rents and cause more intensive development.

Hypothesis 4: Each type of cluster is associated with a certain employment mix and larger, denser and more accessible types have a higher proportion of office workers.

It has already been said that firms will seek locations and physical environments that suit their internal production requirements. This should result in certain physical types of clusters that are associated with certain types of employment. Clusters in the most accessible location, in addition to being larger and denser, should attract a higher proportion of office firms because of their steeper bid-rent functions caused by their relatively high transport costs resulting from their tendency to rely on face-toface contacts (Sullivan, 1990). On the other hand, activities like manufacturing and warehousing, with comparatively low transport costs, should be excluded from the higher density, higher rent areas in what has been referred to as the downtown sorting-out process (Vance, 1971).
Hypothesis 5: Types of clusters that are larger, denser or located near fixed-rail transit stations, will generate a lower proportion of single-occupant auto trips.

The commuter chooses the mode that minimises the total cost of travel, which is a combination of time and monetary costs (Sullivan, 1990). Alternatives to auto driving become more attractive as the total cost of auto driving increases and the total cost of alternatives decreases. Commuters to clusters that are larger, denser or located near a transit station will often experience higher total costs for auto driving caused by greater traffic congestion and parking costs (Cervero, 1989). They also will experience lower total costs for alternatives such as transit and car-pooling because of the better service, easier access to car-pooling partners, availability of ride-sharing programmes and pedestrian access to daytime worker services.

Hypothesis 6: Those elements of urban plans which conform with these hypotheses are more likely to be implemented than those elements which do not.

The physical outcomes described by these hypotheses come from forces that shape development in our society. Our tools for implementing plans cannot be divorced from this context. Zoning, for example, cannot make a cluster grow to a scale or intensity that is significantly greater than the market will support or political forces will allow. Conversely, zoning cannot prevent a cluster from growing by much less than these forces. For this reason, plans for large clusters at inaccessible locations, or plans that would prevent the most accessible clusters from growing, will have diffculties being implemented. Political movements sometimes will withstand pressure for development, and well-conceived incentive packages can stimulate markets; however, plans that go against basic political and economic forces will face stiff impediments to their implementation. 
Table 2. Summary of Toronto's 1980 plan for suburban centres

\begin{tabular}{ll}
\hline Centres & Characteristics \\
\hline Major centres (2) & $\begin{array}{l}\text { Multifunctional in land use; } \\
\text { compact, pedestrian-oriented; } \\
\text { intensive, higher density development; } \\
\text { located along the rapid transit system; } \\
\text { greater reliance on transit trips; } \\
\text { significant residential component. } \\
40000 \text { jobs; } 8750000 \mathrm{ft}^{2} \text { by } 200 \mathrm{l}\end{array}$ \\
& $\begin{array}{l}\text { Same as above but fewer jobs, serving a smaller area; } \\
12-24000 \text { jobs; } 3750000 \mathrm{ft}^{2} \text { by } 2001 .\end{array}$ \\
Intermediate centres (4) & $\begin{array}{l}\text { Oriented to expressways; } \\
\text { lower density development; } \\
\text { originally part of industrial areas; } \\
\text { restricted variety of uses. }\end{array}$ \\
Principal foci (2) & $\begin{array}{l}\text { At the site of existing civic centres; } \\
\text { focus for commercial and community activities. }\end{array}$ \\
Area municipal centres & $\begin{array}{l}\text { Areas with local significance; } \\
\text { not designated in offial plan; } \\
\text { designated by local municipalities. }\end{array}$ \\
Office/retail/institutional uses near & $\begin{array}{l}\text { Within } 300 \text { m of rapid transit stations; } \\
\text { municipal responsibility; } \\
\text { of a scale and density to not compete with Centers. }\end{array}$ \\
\hline
\end{tabular}

Source: Metropolitan Planning Department, 1989.

\section{The Case of Toronto}

The hypotheses were tested in a study of the metropolitan Toronto region. The Municipality of Metropolitan Toronto adopted one of North America's first multicentred regional plans in 1980 and is seen as a leader in this regard. Its recognition in this area, (Pill, 1983; Cervero, 1985; Attoe, 1987), its governmental capacity to implement the plan and the passage of enough time to make a reasonable assessment, all make Toronto an attractive location for an initial test of the hypotheses.

The clusters described in the Toronto plan are summarised in Table 2. The plan identifies various types of centres and their location, employment, physical and transport characteristics.

\section{Methods and Results}

The study used a correlational research design to examine all 60 suburban office clusters located in the Toronto region. A cluster was defined as any group of two or more office buildings separated by onequarter of a mile or less and located outside the regional central business district. The data were provided by the Metropolitan Planning Department Office Data Bank which maintains a complete inventory of office buildings including their size, location, age and other useful information.

\section{The Taxonomy}

The first hypothesis was that there are discrete physical types of office clusters. 
Table 3. Variables used in the cluster analysis

\begin{tabular}{ll}
\hline Variable & Definition \\
\hline $\begin{array}{l}\text { Urban form variables } \\
\text { SIZE }\end{array}$ & $\begin{array}{l}\text { Square feet of office space in an office cluster. } \\
\text { GeNSITY }\end{array}$ \\
$\begin{array}{l}\text { Gross density of office space in a cluster. Measured by dividing SIZE by } \\
\text { in each cluster. }\end{array}$ \\
Location/accessibility variables \\
FWY & $\begin{array}{l}\text { Whether or not the cluster is located within } 0.5 \text { mile straight-line } \\
\text { distance from a freeway or expressway interchange. ( } 1=\text { yes, } 0=\text { no). } \\
\text { Whether or not the cluster is located within } 0.5 \text { mile straight-line } \\
\text { distance from a freeway or expressway interchange. ( } 1=\text { yes, } 0=\text { no). } \\
\text { Whether or not the cluster is located within walking distance }(0.25 \text { mile) } \\
\text { from a subway station. }(1=\text { yes, } 0=\text { no). }\end{array}$ \\
SWAY & $\begin{array}{l}\text { Straight-line distance in miles from the regional CBD to the cluster } \\
\text { centre. }\end{array}$ \\
\hline
\end{tabular}

Table 4. Types of suburban office clusters in Toronto

\begin{tabular}{lcccc}
\hline Cluster type & Number & Percentage & $\begin{array}{c}\text { Office space } \\
\left(\mathrm{m} \mathrm{ft}^{2}\right)\end{array}$ & Percentage \\
\hline Common & 34 & 57 & 16.7 & 34 \\
Interchange & 13 & 22 & 12.2 & 25 \\
Outlying & 5 & 8 & 2.0 & 4 \\
Secondary transit & 4 & 7 & 4.5 & 9 \\
Primary transit & 3 & 5 & 11.5 & 23 \\
Major auto & 1 & 2 & 2.2 & 4 \\
Total & 60 & 100 & 49.1 & 100 \\
\hline
\end{tabular}

This was tested using cluster analysis (Aldenderfer, 1984; Dillon and Goldstein, 1984). The variables that were used are given in Table $3 .^{2}$

Table 4 lists the six resulting types of office clusters and their names, frequencies and share of the total suburban office stock. Figure 1 shows their location.

A discriminant analysis was performed to test the validity of the cluster analysis (Klecka, 1980). The six variables from the cluster analysis were used to distinguish among the six types of clusters. The discriminant analysis grouped 58 per cent of the cases correctly. This is a considerable improvement over the 17 per cent accuracy that would be expected if cases were assigned to groups by chance. DENSITY, SIZE and DIST, in that order, were the most important variables for discriminating between groups. Grouping errors were caused by incorrectly assigning members among the Interchange, Common and Secondary Transit groups, indicating greater difficulty in distinguishing among these types of clusters. In the other three groups, 100 per cent of the members were correctly classified.

Most clusters fell into one of two types which were not highly distinguishable from one another by the discriminant analysis. While six distinct groups can be identified, only 20 per cent of the clusters were highly different from the others. 


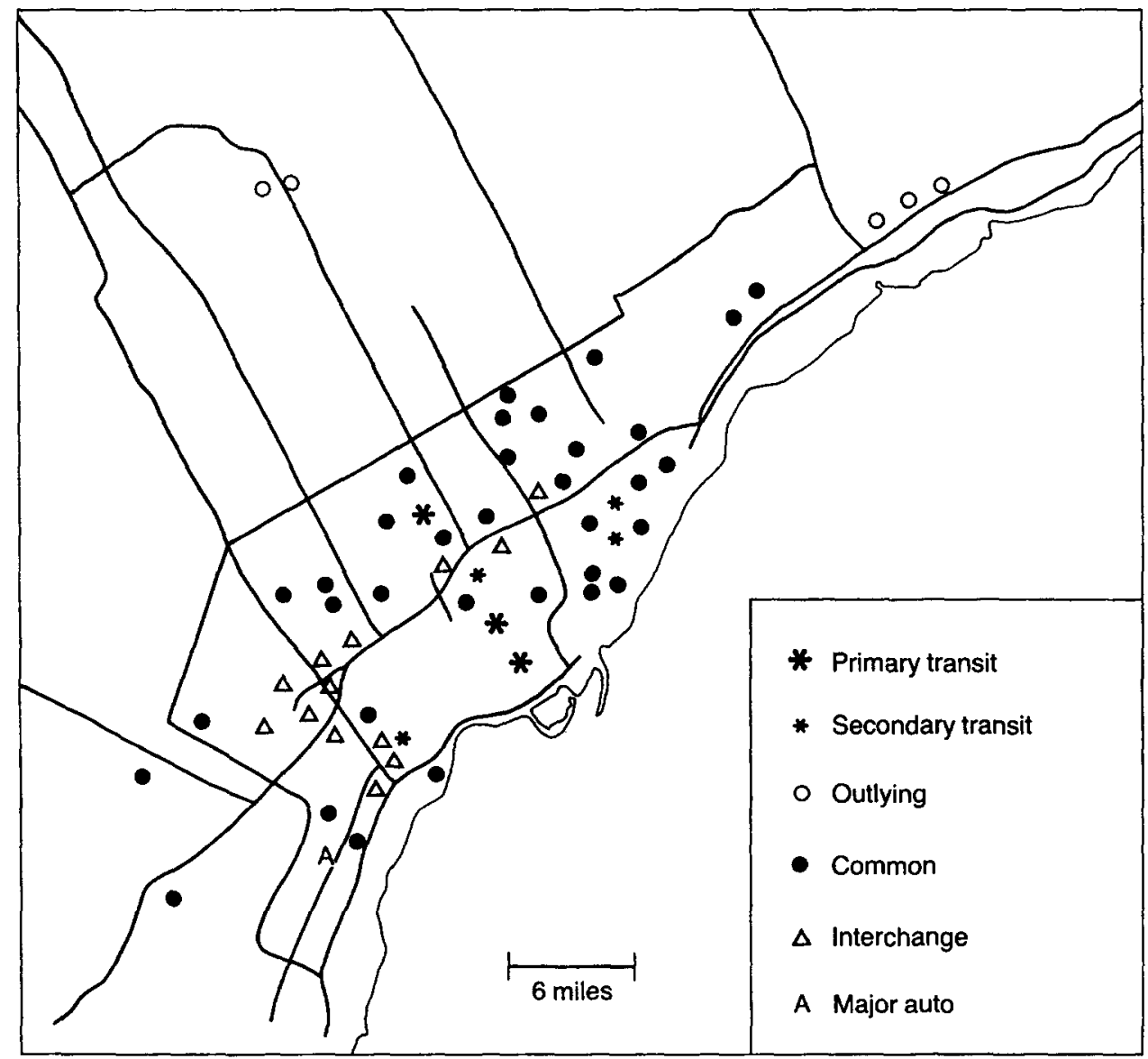

Figure 1. Office clusters in metropolitan Toronto.

Large variations in the size, location and density of the types are apparent from the descriptive statistics shown in Table 5 . Median sizes varied from $108000 \mathrm{ft}^{2}$ for Outlying Clusters to over $4 \mathrm{~m} \mathrm{ft}^{2}$ for Primary Transit Clusters. Mean densities varied nearly five-fold from $5933 \mathrm{ft}^{2}$ per acre for Common Clusters to $31219 \mathrm{ft}^{2}$ per acre for Primary Transit Clusters. Median distances from the CBD ranged from 28 miles for Outlying Clusters to 2.7 miles for Primary Transit Clusters.

Each type of cluster had some characteristics that set it apart from others. These distinguishing characteristics were used to give each type of cluster a name that suggests it most distinctive characteristic. Outlying Clusters were notable for their great distance from the CBD and their tendency to locate away from freeways or expressways. Interchange Clusters could be identified by their closeness to freeway interchanges. They also were the only smaller type of cluster that typically located close to a freeway. ${ }^{3}$ Common Clusters, as their name implies, were notable by their frequent occurrence. Primary and Secondary Transit Clusters were distinguished by being located within walking distance of a subway station. They also were found closer to the Central Business District and were larger and denser than other types of clusters, except for the Major Auto Cluster.

Thus, Toronto's suburban office clusters can be grouped into six distinct types based on their physical characteristics. However, some overlapping between the 
Table 5. Descriptive statistics for cluster types

\begin{tabular}{|c|c|c|c|c|c|c|}
\hline & INTCHG & COMMN & PRIMTRN & SECTRN & OUTLY & MAJAUTO \\
\hline$N$ & 13 & 34 & 3 & 4 & 5 & 1 \\
\hline $\begin{array}{l}\text { SIZE }\left(000 \mathrm{ft}^{2}\right) \\
\text { Mean } \\
\text { Median } \\
\text { Standard deviation } \\
\text { Range }\end{array}$ & $\begin{array}{r}939 \\
334 \\
1043 \\
2838\end{array}$ & $\begin{array}{r}491 \\
289 \\
492 \\
1694\end{array}$ & $\begin{array}{r}3846 \\
4095 \\
807 \\
1557\end{array}$ & $\begin{array}{r}1123 \\
848 \\
955 \\
2200\end{array}$ & $\begin{array}{r}398 \\
108 \\
469 \\
1082\end{array}$ & $\begin{array}{l}2203 \\
2203 \\
\overline{0.00}\end{array}$ \\
\hline $\begin{array}{l}\text { DENSITY }\left(\mathrm{ft}^{2} / \mathrm{acre}\right) \\
\text { Mean } \\
\text { Median } \\
\text { Standard deviation } \\
\text { Range }\end{array}$ & $\begin{array}{r}7491 \\
8286 \\
3805 \\
11282\end{array}$ & $\begin{array}{r}5933 \\
5752 \\
3324 \\
10801\end{array}$ & $\begin{array}{r}31219 \\
28297 \\
7237 \\
13561\end{array}$ & $\begin{array}{r}10199 \\
11075 \\
3419 \\
7244\end{array}$ & $\begin{array}{l}8070 \\
8664 \\
1915 \\
4341\end{array}$ & $\begin{array}{c}25235 \\
25235 \\
\overrightarrow{0.00}\end{array}$ \\
\hline $\begin{array}{l}\text { FREEWAY }(1=\text { yes, } \\
\text { Mean } \\
\text { Median } \\
\text { Mode } \\
\text { Standard deviation } \\
\text { Range }\end{array}$ & $\begin{aligned} & 0= \text { no) } \\
& 1.00 \\
& 1.00 \\
& 1.00 \\
& 0.00 \\
& 0.00\end{aligned}$ & $\begin{array}{l}0.50 \\
0.50 \\
0.00 \\
0.51 \\
1.00\end{array}$ & $\begin{array}{l}1.00 \\
1.00 \\
1.00 \\
0.00 \\
0.00\end{array}$ & $\begin{array}{l}0.50 \\
0.50 \\
0.00 \\
0.58 \\
1.00\end{array}$ & $\begin{array}{l}0.00 \\
0.00 \\
\mathbf{0 . 0 0} \\
0.00 \\
0.00\end{array}$ & $\begin{array}{l}1.00 \\
1.00 \\
1.00 \\
-0.00\end{array}$ \\
\hline $\begin{array}{l}\text { INTERCHANGE } 1= \\
\text { Mean } \\
\text { Median } \\
\text { Mode } \\
\text { Standard deviation } \\
\text { Range }\end{array}$ & $\begin{array}{c}=\text { yes, } 0=\mathbf{n c} \\
1.00 \\
1.00 \\
1.00 \\
0.00 \\
0.00\end{array}$ & $\begin{array}{l}0.00 \\
0.00 \\
0.00 \\
0.00 \\
0.00\end{array}$ & $\begin{array}{l}0.00 \\
0.00 \\
0.00 \\
0.00 \\
0.00\end{array}$ & $\begin{array}{l}0.00 \\
0.00 \\
0.00 \\
0.00 \\
0.00\end{array}$ & $\begin{array}{l}0.00 \\
0.00 \\
0.00 \\
0.00 \\
0.00\end{array}$ & $\begin{array}{l}0.00 \\
0.00 \\
0.00 \\
- \\
0.00\end{array}$ \\
\hline $\begin{array}{l}\text { SUBWAY }(1=\text { yes, } 0 \\
\text { Mean } \\
\text { Median } \\
\text { Mode } \\
\text { Standard deviation } \\
\text { Range }\end{array}$ & $\begin{array}{c}=\text { no) } \\
0.00 \\
0.00 \\
\mathbf{0 . 0 0} \\
0.00 \\
0.00\end{array}$ & $\begin{array}{l}0.00 \\
0.00 \\
0.00 \\
0.00 \\
0.00\end{array}$ & $\begin{array}{l}1.00 \\
1.00 \\
1.00 \\
0.00 \\
0.00\end{array}$ & $\begin{array}{l}1.00 \\
1.00 \\
1.00 \\
0.00 \\
0.00\end{array}$ & $\begin{array}{l}0.00 \\
0.00 \\
0.00 \\
0.00 \\
0.00\end{array}$ & $\begin{array}{l}0.00 \\
0.00 \\
0.00 \\
\overrightarrow{0.00}\end{array}$ \\
\hline $\begin{array}{l}\text { DISTANCE FROM } \\
\text { Mean } \\
\text { Median } \\
\text { Standard deviation } \\
\text { Range }\end{array}$ & $\begin{array}{c}\text { CBD (mile } \\
9.8 \\
9.5 \\
2.2 \\
7.5\end{array}$ & $\begin{array}{r}11.5 \\
10.5 \\
4.6 \\
16.8\end{array}$ & $\begin{array}{l}4.2 \\
2.7 \\
3.0 \\
5.3\end{array}$ & $\begin{array}{l}7.7 \\
7.2 \\
1.5 \\
3.4\end{array}$ & $\begin{array}{r}28.2 \\
28.0 \\
0.5 \\
1.0\end{array}$ & $\begin{array}{c}15.00 \\
15.00 \\
- \\
0.00\end{array}$ \\
\hline
\end{tabular}

Note: The best measures of central tendency are given in bold (Norusis, 1986).

groups is apparent. This suggests that it might also be fruitful to think about clusters as lying along several different continua, each describing a different physical characteristic. Nevertheless, each type of cluster did have some unique properties that distinguished it from the others.

\section{Hierarchy}

The second hypothesis was that different types of clusters fall into size- or intensitybased hierarchies, with the number of clusters of a given type inversely related to its typical size and density. This was tested by measuring the number, median size and median density of each type of cluster on an ordinal scale and then measuring the degree of association between their ranking for each variable using Goodman and Kruskal's gamma (Norusis, 1986). ${ }^{4}$

The results, given in Table 6, support the hypothesis that the frequency of a cluster type decreases as its size or density increases. However, the association, was imperfect indicating that a hierarchy did 
Table 6. Degree of association between ordinal values for the frequency, size and density of cluster types

\begin{tabular}{lc}
\hline & Gamma \\
\hline Frequency by size & -0.60 \\
Frequency by density & -0.87 \\
\hline
\end{tabular}

not strictly apply. The most common type was the least dense, but it was not the smallest, and the least common type was not the largest or the densest. It is more accurate to say the most common type of cluster was the least dense and among the smallest and that the least common type was among the densest and largest.

\section{The Effect of Accessibility}

The third hypothesis was that larger and denser types of clusters locate at more accessible locations. Simple linear regression statistics were used as the test. The results are presented in Table 7.

The regression lines predicted that the types of clusters that locate near a freeway or subway station will be about $1.75 \mathrm{~m} \mathrm{ft}^{2}$ larger and 9-13000 $\mathrm{ft}^{2} /$ acre denser than other types of clusters. They also predicted that a 1 -mile increase in distance from the CBD causes a $90000 \mathrm{ft}^{2}$ decline in typical size and a $600 \mathrm{ft}^{2}$ acre decline in density.

The large unexplained variations indicated that accessibility, at least as measured by these indicators, did not fully explain the typical size and density of a cluster type. More work is needed to evaluate other factors that may affect size and density. They probably include zon- ing, governance, local politics, developer entrepreneurship, ownership patterns and transport facilities. However, the analysis supported the hypothesis that accessibility has a significant impact on the typical size and density of a type of office cluster.

\section{Cluster Types and Employment}

The fourth hypothesis was that each type of cluster is associated with a certain employment mix and the larger, denser and more accessible types of clusters will have a larger proportion of office workers.

The hypothesis was tested using data from the census of employment conducted in 1987 by the Metropolitan Toronto Planning Department. Table 8 gives the typical mix of workers for the four types of office cluster that could be used for this part of the study. ${ }^{5}$ If the hypothesis is correct then there should have been different employment mixes from type to type. Differences were found in office, manufacturing and retail employment. Primary Transit clusters are most different with very high office and very low manufacturing employment levels. The differences between most other employment categories were small.

Table 8 also presents a variable called Employment Entropy (EMPENT). The variable was created to reflect the amount of employment mix in each cluster. It was patterned after the Use Entropy Index used by Cervero (1989) to measure land use mix within suburban employment centres. EMPENT is a logarithmic index ranging from 0 for total homogeneity, with all employment in one category, to 0.78 for maximum heterogeneity, with an even

Table 7. Regression statistics for size, density and accessibility $(N=6)$

\begin{tabular}{lcccccccc}
\hline & \multicolumn{2}{c}{ FWY } & \multicolumn{2}{c}{ ICHNG } & \multicolumn{2}{c}{ SWAY } & \multicolumn{2}{c}{ DIST } \\
& $b$ & $r^{2}$ & $b$ & $r^{2}$ & $b$ & $r^{2}$ & $b$ & $r^{2}$ \\
\hline SIZE & 1.8 & 0.40 & -1.2 & 0.09 & 1.7 & 0.32 & -0.09 & 0.28 \\
DENSITY & 13.2 & 0.46 & -8.6 & 0.11 & 9.0 & 0.19 & -0.46 & 0.14 \\
\hline
\end{tabular}


Table 8. Descriptive statistics for employment percentages

\begin{tabular}{|c|c|c|c|c|}
\hline & INTCHG & COMMON & PRIMTRN & SECTRN \\
\hline$N$ & 10 & 22 & 3 & 4 \\
\hline $\begin{array}{l}\text { OFFICE } \\
\text { Mean } \\
\text { Median } \\
\text { Standard deviation }\end{array}$ & $\begin{array}{l}41 \\
37 \\
22\end{array}$ & $\begin{array}{l}36 \\
29 \\
16\end{array}$ & $\begin{array}{l}76 \\
75 \\
05\end{array}$ & $\begin{array}{l}43 \\
47 \\
13\end{array}$ \\
\hline $\begin{array}{l}\text { MANUFACTURING } \\
\text { Mean } \\
\text { Median } \\
\text { Standard deviation }\end{array}$ & $\begin{array}{l}23 \\
\mathbf{2 3} \\
19\end{array}$ & $\begin{array}{l}28 \\
32 \\
24\end{array}$ & $\begin{array}{l}1 \\
1 \\
0\end{array}$ & $\begin{array}{l}23 \\
24 \\
19\end{array}$ \\
\hline $\begin{array}{l}\text { INSTITUTIONAL } \\
\text { Mean } \\
\text { Median } \\
\text { Standard deviation }\end{array}$ & $\begin{array}{l}6 \\
2 \\
8\end{array}$ & $\begin{array}{r}10 \\
7 \\
9\end{array}$ & $\begin{array}{l}4 \\
4 \\
3\end{array}$ & $\begin{array}{l}6 \\
4 \\
4\end{array}$ \\
\hline $\begin{array}{l}\text { RETAIL } \\
\text { Mean } \\
\text { Median } \\
\text { Standard deviation }\end{array}$ & $\begin{array}{r}17 \\
8 \\
22\end{array}$ & $\begin{array}{r}14 \\
14 \\
7\end{array}$ & $\begin{array}{l}7 \\
7 \\
2\end{array}$ & $\begin{array}{r}14 \\
15 \\
4\end{array}$ \\
\hline $\begin{array}{l}\text { SERVICE } \\
\text { Mean } \\
\text { Median } \\
\text { Standard deviation }\end{array}$ & $\begin{array}{r}11 \\
10 \\
7\end{array}$ & $\begin{array}{r}12 \\
10 \\
8\end{array}$ & $\begin{array}{l}9 \\
8 \\
2\end{array}$ & $\begin{array}{l}9 \\
8 \\
5\end{array}$ \\
\hline $\begin{array}{l}\text { RECREATIONAL } \\
\text { Mean } \\
\text { Median } \\
\text { Standard deviation }\end{array}$ & $\begin{array}{l}3 \\
1 \\
5\end{array}$ & $\begin{array}{l}2 \\
1 \\
2\end{array}$ & $\begin{array}{l}2 \\
1 \\
1\end{array}$ & $\begin{array}{l}4 \\
1 \\
7\end{array}$ \\
\hline $\begin{array}{l}\text { EMPLOYMENT ENTROPY INDEX } \\
\text { Mean } \\
\text { Median } \\
\text { Standard deviation }\end{array}$ & $\begin{array}{l}\mathbf{0 . 5 1} \\
0.55 \\
0.12\end{array}$ & $\begin{array}{l}\mathbf{0 . 5 6} \\
0.58 \\
0.08\end{array}$ & $\begin{array}{l}\mathbf{0 . 3 4} \\
0.38 \\
0.06\end{array}$ & $\begin{array}{l}\mathbf{0 . 5 8} \\
0.58 \\
0.01\end{array}$ \\
\hline
\end{tabular}

Note: The best measures of central tendency are given in bold. (Norusis, 1986)

mixture among the employment categories. Table 8 shows the substantially lower employment diversity in the Primary Transit clusters compared to the other types which have similar mean scores.

Because the figures in Table 8 were drawn from a sample of the total population of Toronto's clusters, a one-way analysis of variance was used to determine whether the differences between cluster types found in the sample could be attributed to a real difference between cluster types in the population. The results are given in Table 9. ${ }^{6}$ Both Percent Office and Employment Entropy exhibited significant results which indicated that the observed differences between types could be ex- pected to hold for the whole population of Toronto office clusters.

The second part of the hypothesis was that the larger, denser and more accessible types of clusters are skewed toward office employment. This was tested by calculating the correlation coefficients which are given in Table 10. The figures show that as the size, density and elements of accessibility increased, the employment mix became less even and leaned heavily toward office work. The results contradicted several of the regional plans reviewed for the study which planned for greater mixing of land uses in their largest types of clusters. In fact, the largest types of clusters were the least evenly mixed places in terms of employment. 
Table 9. Results of one-way analysis of variance on employment mix

\begin{tabular}{lcc}
\hline Employment & $F$-ratio & $F$-probability \\
\hline PCT OFFICE & 5.3 & 0.004 \\
PCT MANUFACTURING & 1.4 & 0.268 \\
PCT RETAIL & 0.5 & 0.708 \\
PCT INSTITUTIONAL & 0.9 & 0.471 \\
PCT SERVICE & 0.3 & 0.846 \\
PCT RECREATION & 0.8 & 0.493 \\
EMP ENTROPY INDEX & 5.3 & 0.004 \\
\hline
\end{tabular}

Table 10. Correlation coefficients for physical characteristics and percentage of office workers $(\mathrm{N}=6)$

\begin{tabular}{lrr}
\hline & PCTOFF & EMPENT \\
\hline SIZE & 0.80 & -0.93 \\
DENSITY & 0.86 & -0.94 \\
FWY & 0.49 & -0.77 \\
ICHNG & -0.28 & 0.08 \\
SWAY & 0.69 & -0.40 \\
DIST & -0.84 & 0.78 \\
\hline
\end{tabular}

\section{Types and Transit}

The fifth hypothesis was that there is a lower proportion of single-occupant vehicle trips made by cluster types that are larger, denser, have more mixed employment, or are located near a fixed-rail transit station. This was tested by examining origin-destination data for the traffic analysis zones in which the clusters were located. Descriptive statistics for travel mode splits at each type of cluster are given in Table 11. Contrary to the notion of the 'transit-oriented centre', most of the trips, even to the Primary and Secondary Transit clusters, were made by auto drivers. However, the transit clusters did have lower single-occupant vehicle (SOV) use which was compensated for by greater transit use. Trips by auto passengers (carpooling) remained roughly the same across all types of clusters.

Simple linear regressions were used to test whether size, density, proximity to a subway station, or employment mix could be used to predict the percentage of trips made by auto drivers. Table 12 gives the results. Several variables were associated with the percentage of auto drivers. The best predictor was SWAY which explained 94 per cent of the variation in the percentage of auto drivers. Types of clusters near a subway station were predicted to generate over 12 per cent fewer trips by auto drivers.

When the effect of SWAY was held constant, the importance of the other factors declined, but DIST and SIZE still made some difference. Table 13 gives the regression statistics separately for the types with and without subway service. DIST was important in both cases but more so for the cluster types with subway service. The more remote subway stations had a higher percentage of trips by auto drivers. A 1-mile increase in distance from the CBD increased the percentage of auto drivers by 0.57 per cent at cluster types with subway service and by 0.2 per cent at those without.

SIZE and DENSITY had much less effect on transit use when SWAY was held constant. Among the two, size was more important, particularly for cluster types without subway service, where a size increase of $1 \mathrm{~m} \mathrm{\textrm {ft } ^ { 2 }}$ caused a decrease in auto drivers of 1.1 per cent. The same size change caused half as much decline in auto drivers at cluster types with subway service. A density increase of $10000 \mathrm{ft}^{2} /$ acre caused a decline in auto drivers of less than 1 per cent for cluster types with or without subway service.

Thus, the primary factor affecting the 
Table 11. Descriptive statistics for travel mode percentages

\begin{tabular}{lcccccc}
\hline & INTCHG & CMN & PRMTRN & SECTRN & OUTLR & MAJAUTO \\
\hline$N$ & 13 & 31 & 3 & 4 & 4 & 1 \\
AUTO DRIVERS & & & & & & \\
Mean & $\mathbf{7 6}$ & $\mathbf{7 5}$ & $\mathbf{6 3}$ & $\mathbf{6 5}$ & $\mathbf{7 9}$ & $\mathbf{7 5}$ \\
Median & 81 & 75 & 64 & 66 & 80 & 75 \\
Standard deviation & 8.1 & 6.5 & 3.2 & 7.2 & 3.2 & 0 \\
AUTO PASSENGERS & & & & & & \\
Mean & 11 & 9 & 7 & 9 & 12 & 9 \\
Median & $\mathbf{1 0}$ & $\mathbf{9}$ & $\mathbf{6}$ & $\mathbf{8}$ & $\mathbf{1 0}$ & $\mathbf{9}$ \\
Standard deviation & 2.2 & 3.1 & 1.7 & 1.8 & 5.7 & 0 \\
TRANSIT & & & & & & \\
Mean & 12 & 13 & 26 & 23 & 2 & 15 \\
Median & $\mathbf{1 1}$ & $\mathbf{1 2}$ & $\mathbf{2 4}$ & $\mathbf{2 3}$ & $\mathbf{2}$ & $\mathbf{1 5}$ \\
Standard deviation & 5.1 & 6.3 & 4.3 & 5.1 & 1.5 & 0 \\
OTHER & & & & & & \\
Mean & 1 & $\mathbf{3}$ & 4 & 4 & 7 & 1 \\
Median & $\mathbf{1}$ & $\mathbf{4}$ & $\mathbf{4}$ & $\mathbf{4}$ & $\mathbf{7}$ & $\mathbf{1}$ \\
Standard deviation & 0.5 & 0.7 & 1.2 & 2.1 & 1.7 & 0 \\
\hline
\end{tabular}

Note: The best measures of central tendency are given in bold. (Norusis, 1986)

Table 12. Regression statistics between physical factors and the percentages of trips made by auto drivers

\begin{tabular}{lrc}
\hline Variable & \multicolumn{1}{c}{$b$} & $r^{2}$ \\
\hline FWY & -1.7 & 0.02 \\
ICHNG & 4.6 & 0.08 \\
SWAY & -12.3 & 0.94 \\
DIST & 0.6 & 0.60 \\
SIZE & -2.8 & 0.45 \\
DENSITY & -0.3 & 0.29 \\
\hline
\end{tabular}

Table 13. Regression statistics between physical factors and the percentage of trips made by auto drivers, holding SWAY constant

\begin{tabular}{lrrrr}
\hline & \multicolumn{2}{c}{ SWAY } & \multicolumn{2}{c}{ No SWAY } \\
Variable & \multicolumn{2}{c}{$(n=2)$} & \multicolumn{2}{c}{$(n=4)$} \\
& $b$ & $r^{2}$ & \multicolumn{1}{c}{$b$} & $r^{2}$ \\
\hline FWY & -2.00 & 1 & -1.50 & 0.21 \\
ICHNG & - & $\frac{1}{0.33}$ & 0.01 \\
DIST & 0.57 & 1 & 0.20 & 0.78 \\
SIZE & -0.61 & 1 & -1.10 & 0.28 \\
DENSITY & -0.09 & 1 & -0.08 & 0.15 \\
\hline
\end{tabular}

percentage of auto drivers for a given type of cluster was the availability of subway service. Size, density and distance had some additional effect but, within the ranges considered here, they were less important than location.

If this is true, then as long as certain size and density thresholds are exceeded, transit service may be the most important physical planning policy variable for encouraging transit use. This could make it possible to achieve nearly as much transit ridership from more moderately sized clusters, like the Secondary Transit Clusters described here, as long as they exceed certain size and density thresholds. This could provide the benefit of reducing localised auto congestion around larger clusters without sacrificing reductions in SOV use. An important condition is that a certain minimum size and density threshold must be exceeded. The minima for the Secondary Transit Clusters studied here were $850000 \mathrm{ft}^{2}$ in size and $10000 \mathrm{ft}^{2} /$ gross acre in density. It is possible that Secondary Transit Clusters with a much lower size or density, may not reduce auto usage even with subway service.

Other policy-related factors that have been found to be important for mode shares were not included in this study. The presence of ride-sharing programmes and co-ordinators, and the price and supply of 
parking are two important ones (Cervero, 1989). These and other demand management measures, together with transit service, size and density could further reduce the share of auto drivers.

\section{Plan v. Reality}

The final hypothesis was that the elements of plans which conform with the above stated hypotheses are more likely to be implemented than those elements which do not. The Toronto Plan contained several concepts which did not conform with the hypotheses including the location of large and dense clusters in less accessible locations, the location of smaller clusters in highly accessible locations and the assumption that the largest clusters will have more evenly mixed employment. In these instances, actual development followed the hypotheses more closely than the original plan. This generated a number of deviations between the plan and actual experience which are summarised in Table 14.

Primary Transit Clusters in Toronto actually developed closer to the CBD and had less diverse employment than the plan envisioned. The plan located Primary Transit Clusters, which it called Major Centres, in comparatively remote locations, contrary to the third hypothesis. It also expected them to have the greatest level of land use and employment mixing, contrary to the fourth hypothesis. In fact what occurred was consistent with the both hypotheses-Primary Transit Clusters grew in more centrally located sites and had employment that skewed toward office work, and the more remote sites even though they were planned to be Primary Transit Centres, grew more slowly into Secondary Transit Centres.

The experience with the Secondary Transit Clusters, called Intermediate Centres in the plan, diverged from the plan even further than the experience with Primary Transit Clusters. The plan correctly projected their number, their greater transit usage and their multifunctional character. However, they were larger, less dense, and farther removed from the CBD than called for in the original plan. According to the 1980 plan they were to have been $325000 \mathrm{ft}^{2}$ in size by 1987 , when the data for this study were collected, roughly the same size as Common Clusters. However, the plan located them at sites with greater than common accessibility-i.e. at subway stations and at lower than average distance from the CBD-which, according to Hypothesis 3, should have caused them to be larger than more common types of clusters. The original plan also expected the density of Secondary Transit Clusters to be comparable to that of the Primary Transit Clusters. This did not occur because the Secondary Transit Clusters actually located in less accessible locations than the Primary Transit Clusters which, according to Hypothesis 3, caused them to develop at comparatively lower densities.

When it comes to office clusters that were not located at subway stations, the plan diverged still farther from reality. Except for six Office Parks and two Principal Foci, and a few undesignated Area Municipal Centres, no reference was made by the plan to smaller, lower density office clusters located away from subway stations. However, consistent with Hypothesis 2 , more than 50 were found.

\section{Conclusion}

The great variety in physical regional plans suggests a lack of urban theory to guide their development. Under these circumstances planned infrastructure and land use investments amount to multi-billiondollar gambles. It may be possible, however, to develop a useful taxonomy of office clusters that can help increase the chance of successful planning by predicting the nature and impact of office development. Various types of clusters might be identified, like species of animals, each with its own habit or characteristic form, habitat or place where it is usually found, and niche or set of relationships with its 


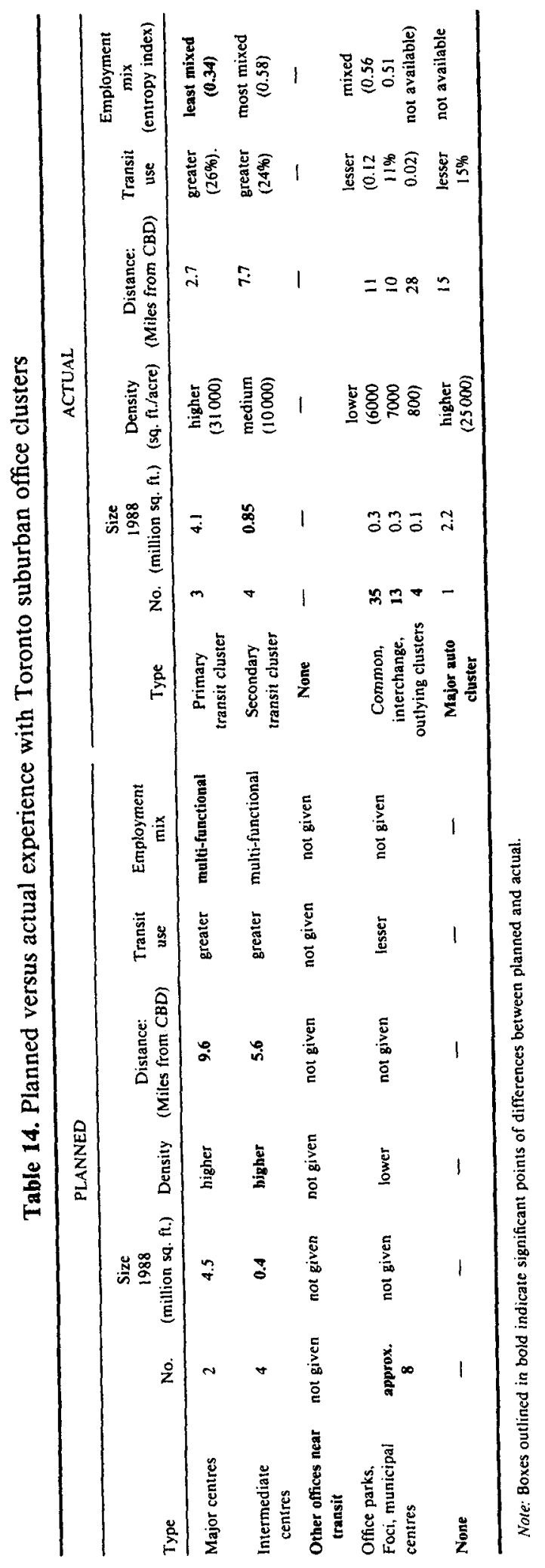


environment. As in the natural world, a given species of clusters would flourish in its normal habitat and struggle in the wrong location.

Toward this end, a taxonomy of suburban office clusters was developed using Toronto as a case-study. A single case is far too limited a basis on which to offer broad policy recommendations. However, the findings from Toronto suggest the following theoretical propositions and planning guidelines.

1. A metropolitan region will contain various types of suburban office clusters that differ in their size, density and location. Therefore, a regional plan should anticipate various types of clusters. In Toronto, six types were found which have been referred to as Primary Transit Clusters, Secondary Transit Clusters, Common Clusters, Interchange Clusters, Major Auto Clusters and Outlying Clusters.

2. The types of clusters will be organised into size- and density-based hierarchies. Therefore, a regional plan should provide for a few of the largest and densest types of clusters and a larger number of small and sparsely developed types.

3. Larger and denser types of clusters are found at more accessible locations. Therefore, plans should locate the largest and densest clusters at more accessible locations.

4. The major employment differences between the types is the mix of office and manufacturing employment. Larger and denser types will have less mixed employment and will be skewed toward office work. Therefore, plans should anticipate that office work will dominate the largest and densest cluster and should focus efforts at mixing employment on smaller clusters.

5. None of the clusters generate mostly transit trips and the largest percentage of transit use occurs at clusters located at transit stations. Moreover, beyond a certain size and density threshold, there may be diminishing returns in terms of improved transit use from increasing cluster size. Therefore, plans should anticipate significant auto usage at all suburban clusters and should emphasise densely developed but moderatesized clusters at transit stations if they seek to encourage transit use and discourage auto congestion.

6. Plans that contradict these propositions, for example, by planning the largest clusters in less accessible locations, will have great difficulty being implemented. Therefore, plans should either conform with these propositions or consciously incorporate strategies to overcome them in order to increase their chance of being implemented.

\section{Notes}

1. In both Pivo (1990) and in this article, an office cluster is defined as two or more office buildings separated by less than onequarter of a mile. A cluster is thus a collectivity of office buildings that are connected by the common trait of being within walking distance of at least one other building in the cluster. Other units of analysis could be used for research on suburban office development patterns such as the individual building, the group of office buildings in a census tract, etc. Ultimately, the choice of units should be based on the research problem in order to be fruitful and not simply follow tradition (Galtung, 1969). The office cluster, as defined here, was selected for several reasons. First, nearly all office buildings occur in clusters, making clusters typically the minimum unit in which offices are found (Pivo, 1990). Secondly, most other geographical units which could be used to define a group of offices-such as corridors, cities, or census tracts-are themselves normally composed of clusters and collecting data at this more aggregated level would make the analysis of individual clusters impossible. Thirdly, this work is intended to assist land use planning for suburban office development which is most frequently concerned with the sizing, spacing and other physical features of contiguous groupings of similar land uses, such as 
a cluster of offices. Fourthly, the transit mode issue in particular, as well as other issues that are related to office development, such as agglomeration for the purpose of easing face-to-face interactions, are logically investigated at the cluster. scale because they relate to the ability to walk within an area.

An important assumption that should not go without questioning is what is the best unit of analysis for planning and research purposes? It might be the case, for example, that it is easier to predict the impacts of development on an individual building or large-area basis than on the basis of the office clusters as defined here. There is a growing recognition that planning at the level of small geographical units is unable to account for the cumulative affects caused by interactions among land uses and the common infrastructure and environmental systems that occur. The possibility of looking at office agglomerations at other levels is explored to some degree in a previous work by the author (Pivo, 1990). In that work, the organisation of clusters into cluster groups, regional sectors and corridors was recognised. However, the potential of this level of structure for predicting traffic patterns or other impacts of office development is still unexplored. Ultimately, it may be that different issues are best understood on different levels.

2. Cluster analysis gathers cases into larger and larger groups in a series of stages until all cases are included in a single group. At each stage an agglomeration coefficient is calculated which measures the distance between the two most dissimilar points of the groups being combined at each stage. The agglomeration is generally stopped when the increase in the agglomeration coefficient becomes large. This occurred at the stage when there were six separate groups of office clusters, just before a 55 per cent increase in the agglomeration coefficient which fell between an 8 and a 10 per cent increase.

3. This is probably a unique quality of the Toronto region and other areas with less developed freeway systems. American regions by comparison have more developed freeway networks (Goldberg and Mercer, 1986) and probably will have more of their small types of clusters near freeways. The improved access would make the small American clusters more competitive with the larger ones which may reduce the office market share, density, size and transit usage of larger US clusters.

4. Gamma is interpreted in a manner similar to a correlation coefficient. For example, a negative relationship between the median size and number of cases, indicates that as the median size of a type increases, its number of cases decreases.

5. Data were collected for 374 traffic zones which ranged in size from 0.1 to 1.2 miles $^{2}$. In most cases the office clusters did not contain all of the employment in the traffic zones and usually 20-30 per cent of the employment was located outside the clusters. About one-third of the 60 clusters were excluded from the analysis because they were located outside the employment census area or shared a traffic zone with other clusters in a way which made it impossible to divide the data among the individual clusters. However, for the four types which remained, their relative proportion in the sample was similar to their proportion in the total population.

6. An $F$-ratio of less than one indicates that the within-group variability is larger than the between-group variability, reducing the likelihood that there are real differences between types. The $F$-probability is the observed significance level or the likelihood of the $F$-ratio occurring by chance.

\section{References}

ALdenderfer, M.S. (1984) Cluster Analysis. Beverly Hills, CA: Sage Publications.

Artibise, A., Wollenterg, J., Hotson, N. and Fallick, A. (1990) Town Centres and the Livable Region: A Strategy for the 1990s. Vancouver: Greater Vancouver Regional District.

ATTOE, W. (1987) Transit, Land Use and Urban Form. Austin, TX: Center for the Study of American Architecture.

BaERwald, T.J. (1982) Land use change in suburban clusters and corridors, Transportation Research Record, 861, pp. 7-12.

Cervero, R. (1985) A tale of two cities: light rail transit in Canada, Journal of Transportation Engineering, 111, pp. 633-650.

Cervero, R. (1989) America's Suburban Centers: The Land Use-Transportation Link. Boston, MA: Unwin Hyman.

City of Phoenix (1985) General Plan for Phoenix 1985/2000. Phoenix, AZ: City of Phoenix.

CLARK, D. (1982) Urban Geography: An Introductory Guide. Baltimore, The Johns Hopkins University Press. 
Daniels, P. (1974) New offices in the suburbs, in: J. Johnson (Ed.) Suburban Growth: Geographical Processes at the Edge of the Western City, pp. 177-200. New York: John Wiley and Sons.

Dillon, W.R. and GoldstenN, M. (1984) Multivariate Analysis: Methods and Applications. New York: John Wiley and Sons.

Dowall, D. E. (1988) Office market research: the case for segmentation, The Journal of Real Estate Development, 4, pp. 34-43.

Galtung, J. (1969) Theory and Methods of Social Research. London: George Allen and Unwin.

GoldBerg, M.A. and Mercer, J. (1986) The Myth of the North American City. Vancouver: University of British Columbia Press.

GoOdall, B. (1972) The Economics of Urban Areas. Oxford: Pergamon Press.

HARTSHORN, T.A. and MULLER, P.O. (1986) Suburban Business Centers: Employment Implications. Washington, DC: US Department of Commerce, Economic Development Administration, Technical Assistant and $\mathrm{Re}$ search Division, Project No. RED-808-G-84 5 (99-7-13616) and Association of American Geographers.

HEMPEL, C. (1965) Fundamentals of taxonomy, in: C. HEMPEL, Aspects of Scientific Explanation and Other Essays in the Philosophy of Science, pp. 137-171. New York: The Free Press.

KENNEDY, M.M. (1979) Generalizing from single case studies. Evaluation Quarterly, 3(4), pp. 661-679.

KLECKA, W.R. (1980) Discriminant Analysis. Beverly Hills, CA: Sage Publications.
LEINBERGER, C.B. (1988) The six types of urban village cores, Urban Land, 47(5), pp. 24-28.

Metropolitan Planning Department, ToRONTO (1980) Official Plan for The Urban Structure Metropolitan Toronto. Toronto: The Municipality of Metropolitan Toronto.

Metropolitan Planning Department, ToRONTO (1988) Metropolitan Plan Review. Toronto: The Municipality of Metropolitan Toronto.

Nachmias, D. and Nachmias, C. (1987) $R e$ search Methods in the Social Sciences, 3rd edn. New York: St Martin's Press.

Norusis, M. (1986) The SPSS Guide to Data Analysis. Chicago, IL: SPSS Inc.

PILL, J. (1983) Emerging activity centers in Metropolitan Toronto, Journal of Advanced Transportation, 17, pp. 301-316.

Pivo, G. (1990) The net of mixed beads: suburban office development in six metropolitan regions, Journal of the American Planning Association, 56, pp. 457-469.

SOUTHERn California Association of Govern. MENTs (1984) Regional Transportation Plan. Los Angeles, CA: Southern California Association of Governments.

Sullivan, A. (1990) Urban Economics. Boston, MA: Irwin.

VANCE, J.E., JR. (1971) Focus on the downtown, in: L. S. Bourne (Ed.) 1971, Internal Structure of the City: Readings on Space and Environment, pp. 112-121. Toronto: Oxford University Press.

Whyte, W.H. (1990) City: Rediscovering the Center. New York: Doubleday. 